\title{
MALToma of minor Salivary gland of lip in a young girl: A case report
}

Rolly Agarwal ${ }^{1}$, Sunil Jondhale ${ }^{1}$, Shamendra Sahu ${ }^{1}$, Amit Bugalia $^{1}$, and Anil Kumar Goel ${ }^{1}$

${ }^{1}$ AIIMS Raipur

June 26, 2020

\begin{abstract}
Mucosa associated lymphoid tissue (MALT) lymphoma is included in extra nodal marginal zone B-cell lymphoma. MALTomas are predominantly seen in adults and rarely reported in children \& adolescents particularly in immunodeficiency state. Here, we are reporting third case of MALT lymphoma of minor salivary glands of lip in a 9-year-old immuno-competent child. The patient had firm mass on right upper lip. PET Scan showed few avid cervical lymph nodes. Microscopic sections and Immunohistochemical staining demonstrated infiltration by a tumor consistent with MALToma. Child was successfully treated with complete resection followed by chemotherapy with no recurrence at 6 month.
\end{abstract}

\section{MALToma of minor Salivary gland of lip in a young girl: A case report}

Rolly Jain ${ }^{1}$, Sunil Jondhale ${ }^{1}$, Samarendra Anand Sahoo ${ }^{2}$, Amit Bugalia ${ }^{3}$, Anil Kumar Goel ${ }^{*}$

${ }^{1}$ Department of Pediatric, All India Institute of Medical Sciences, Raipur

2 Department of Plastic Surgery, All India Institute of Medical Sciences, Raipur

${ }^{3}$ Department of Pathology,All India Institute of Medical Sciences, Raipur

* Correspondence to :

Anil Kumar Goel, Professor \& Head, Department of Pediatrics and PEM, CG, India,

Tel.: +91-9810144784

Email: akgoel.paeds@gmail.com

Text word count 1059;

Abstract word count : 100;

Brief running title : MALToma of minor Salivary gland in young girl

Key words: MALToma, Salivary gland, case report, children

Tables: 0

Figures: 4

\begin{tabular}{ll}
\hline Abbreviations & Abbreviations \\
\hline MALT & Mucosa associated lymphoid tissue \\
MALToma & MALT lymphoma \\
\hline
\end{tabular}




\section{Hosted file}

Manuscript_Maltoma.docx available at https://authorea.com/users/337096/articles/462750maltoma-of-minor-salivary-gland-of-lip-in-a-young-girl-a-case-report

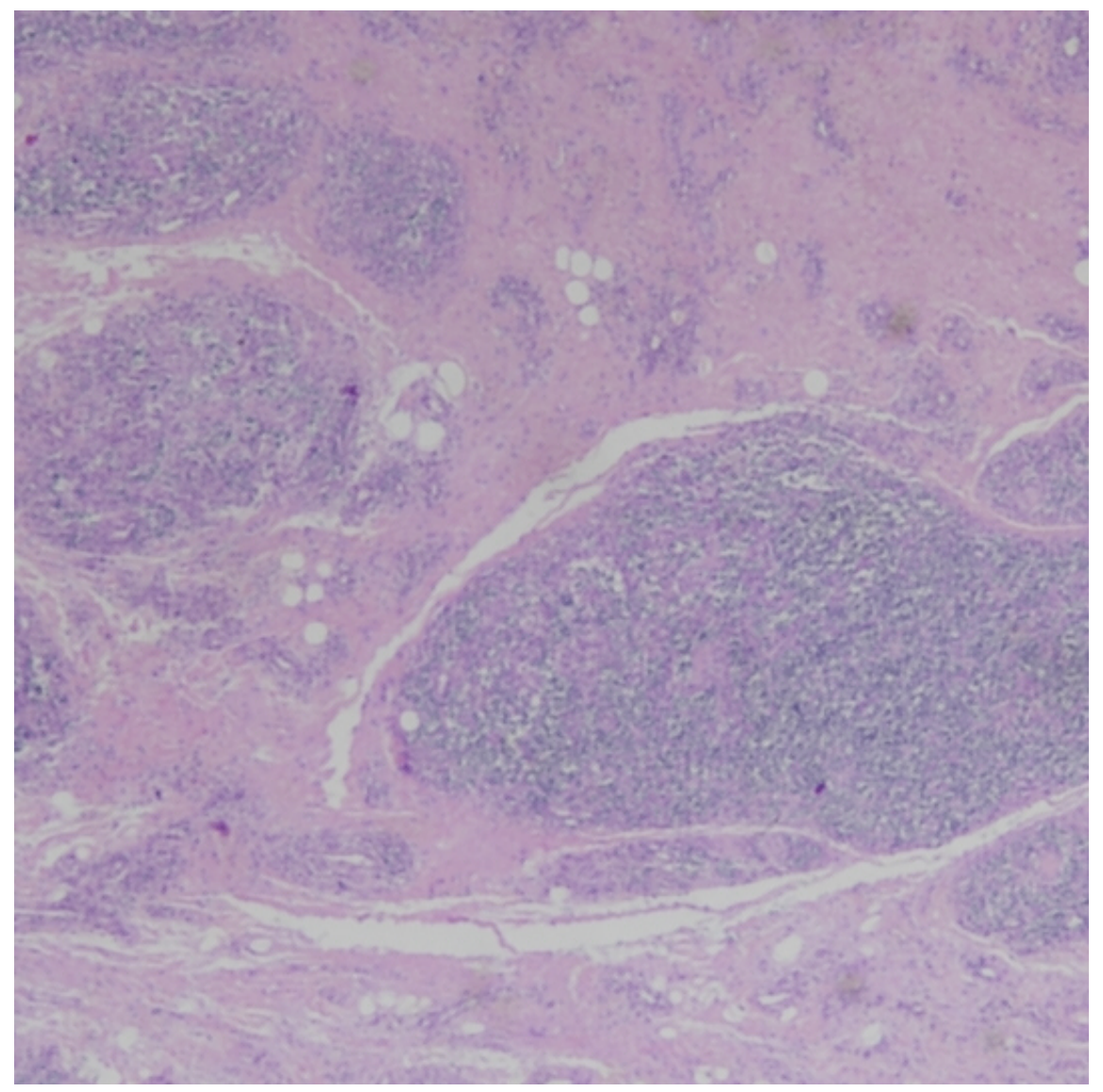




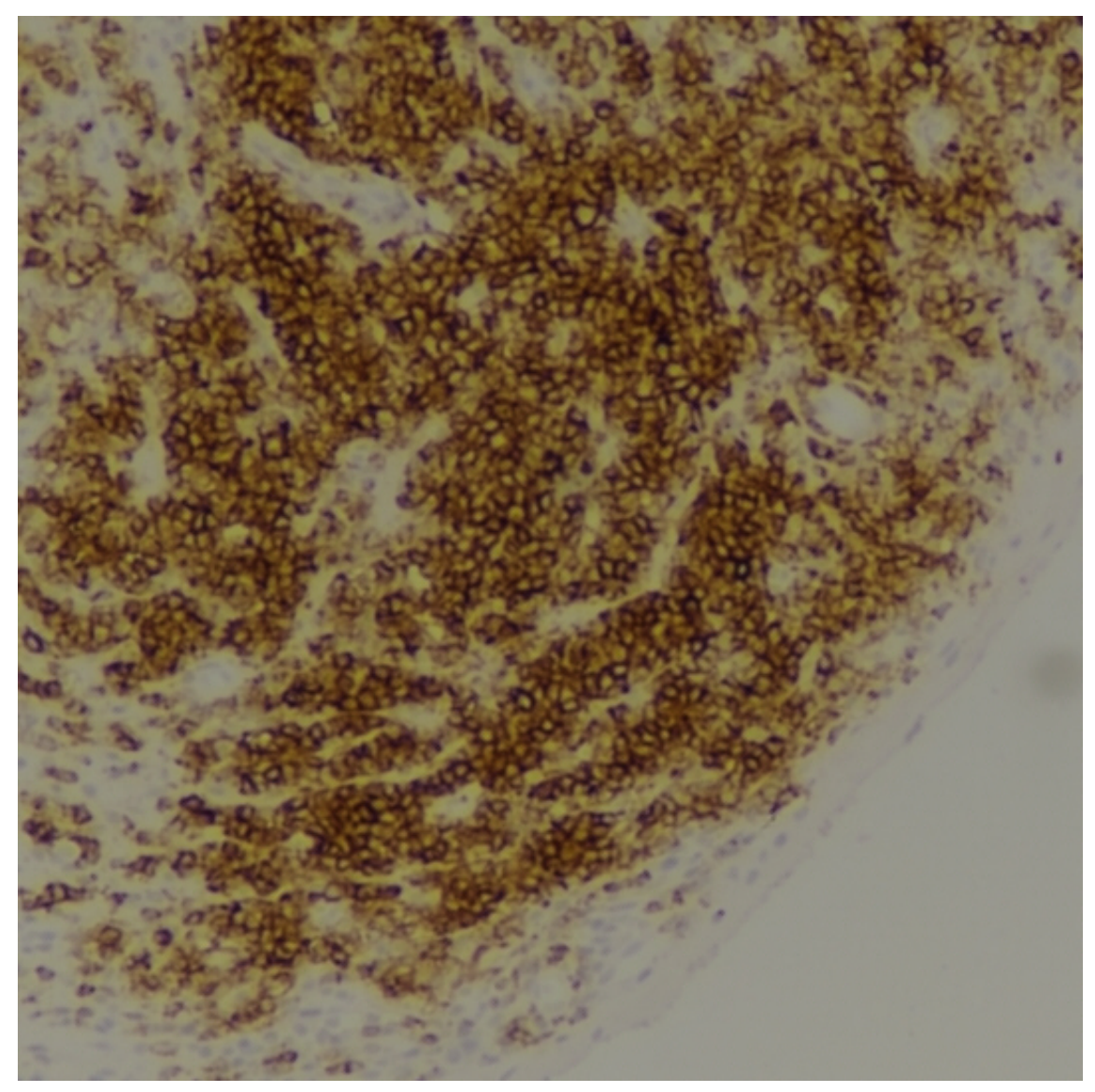

